\title{
ÉPOCAS DE DESSECAÇÃO DE COBERTURAS DE INVERNO EM RELAÇÃO À SEMEADURA DO MILHO: INFESTAÇÃO DE PLANTAS DANINHAS E PRODUTIVIDADE DA CULTURA
}

\section{DESICCATION TIME OF WINTER COVER CROPS IN RELATION TO MAIZE SOWING: WEED INFESTATION AND MAIZE YIELD}

\author{
Alvadi Antonio BALBINOT $\mathrm{JR}^{1}$ \\ Anibal de MORAES ${ }^{2}$ \\ Rogério Luiz BACKES ${ }^{3}$ \\ Adriano Martinho de SOUZA ${ }^{4}$
}

\begin{abstract}
RESUMO
Práticas de manejo que favoreçam o estabelecimento precoce de plantas cultivadas em relação às plantas daninhas são importantes no manejo dessas e, em conseqüência, na redução do uso de herbicidas. A redução do intervalo de tempo entre a dessecação das coberturas de inverno e a semeadura de milho é um dos manejos que podem reduzir a infestação de plantas daninhas estivais, devido ao atraso de estabelecimento das plantas daninhas. O objetivo desse trabalho foi avaliar o efeito de épocas de dessecação de duas coberturas do solo de inverno, em relação à semeadura do milho, sobre a infestação de plantas daninhas e sobre a produtividade da cultura. Para tanto, foi conduzido um experimento em Canoinhas, SC, na safra 2004/05. Avaliaram-se duas culturas de cobertura: azevém e consórcio entre azevém, aveia preta, centeio, ervilhaca comum e nabo forrageiro. Essas culturas foram manejadas quimicamente em cinco épocas: $30,20,10,5$ e 1 dia antes da semeadura do milho em delineamento fatorial $2 \times 5$. O manejo das coberturas de inverno próximo à semeadura da cultura de milho reduziu a densidade e o acúmulo de massa pelas plantas daninhas, conferindo maiores produtividades de grãos.
\end{abstract}

Palavras-chave: Zea mays, interferência, competição, manejo cultural, plantio direto

\begin{abstract}
Practices that facility the crop establishment are important in weed management, consequently reducing herbicide use. A small time among plant cover desiccation and sowing maize is one of the management practices that can reduce weed infestation due to weed establishment retardation. The aim of this work was to evaluate the effect of the cover crop desiccation time in relation to the maize sowing on the weed infestation and maize yield. An experiment was carried out in Canoinhas, SC, Brazil in the season2004/ 05. Ryegrass in a single crop and an intercropping system (ryegrass + black oat + rye + common vetch + oilseed radish) were desiccated in five times: $30,20,10,5$ e 1 day before the maize sowing, in a factorial scheme $2 \times 5$. The cover crop management near to the maize sowing reduced the density and mass accumulation of weeds and improved the maize grain yield.
\end{abstract}

Key-words: Zea mays, interference, competition, cultural management, no tillage system

\footnotetext{
${ }^{1}$ Eng. Agr., MSc., Doutorando do Programa de Pós-Graduação em Agronomia/Produção Vegetal da UFPR; Pesquisador da Epagri, Estação Experimental de Canoinhas, BR 280, km 219,5, bairro Campo da Água Verde, CP 216, 89460-000, Canoinhas, SC. E-mail: balbinot@epagri.rct-sc.br.

${ }^{2}$ Eng. Agr., Dr., Professor Adjunto do Departamento de Fitotecnia e Fitossanitarismo (UFPR).

${ }^{3}$ Eng. Agr., Dr., Pesquisador da Epagri, Estação Experimental de Canoinhas.

${ }^{4}$ Eng. Agr., MSc., Pesquisador da Epagri, Estação Experimental de Canoinhas.
} 


\section{INTRODUÇÃO}

O método de controle de plantas daninhas mais freqüentemente utilizado é o químico, por meio do uso de herbicidas, os quais contribuem expressivamente para aumentar a contaminação do ambiente. Com o intuito de reduzir o uso de herbicidas, medidas preventivas e culturais devem ser adotadas dentro de uma estratégia de controle integrado de plantas daninhas. Nesse sentido, o uso de cobertura do solo em sistema de plantio direto é uma prática que apresenta elevado efeito em suprimir essas plantas (VIDAL e TREZZI, 2004). Na fase de crescimento vegetativo, as culturas de cobertura reduzem a infestação devido à ocupação do nicho (VITTA et al., 1993; RADOSEVICH et al., 1997); depois de manejadas, a cobertura morta sobre o solo dificulta a emergência de várias espécies daninhas devido ao efeito físico de sombreamento (SEVERINO e CHRISTOFFOLETI, 2001). Já a palha em decomposição, através da liberação de substâncias orgânicas, exerce efeito alelopático que pode reduzir a emergência e/ou crescimento de plantas daninhas (TREZZI e VIDAL, 2004) e/ou das próprias culturas agrícolas.

Entre as culturas de cobertura do solo de inverno, a aveia preta (Avena strigosa) e o azevém (Lolium multiflorum) vêm demonstrando elevado potencial em suprimir a emergência e o crescimento de plantas daninhas (ROMAN, 2002). Na cultura do milho, BALBINOT et al. (2005) verificaram que o azevém e o consórcio entre azevém + aveia preta + centeio (Secale cereale) + ervilhaca comum (Vicia sativa) + nabo forrageiro (Raphanus sativus) reduziram a fitomassa acumulada pelas plantas daninhas em aproximadamente cinco e três vezes, respectivamente, em relação ao uso de nabo forrageiro em cultivo solteiro.

Em geral, fitomassa de poáceas apresenta elevada relação $\mathrm{C} / \mathrm{N}$, por isso recomenda-se intervalo mínimo de 20 dias entre a dessecação e a semeadura do milho, evitando a coincidência entre o pico de imobilização de $\mathrm{N}$ pela palha em decomposição com o pico de requerimento de $\mathrm{N}$ pela cultura. Adicionalmente, em situações em que há elevada quantidade de palha, a mesma pode exercer efeito de sombreamento sobre as plantas cultivadas recém emergidas (CONSTANTIN et al., 2005).

Contudo, muitas vezes, esse maior intervalo entre a dessecação e a semeadura provoca elevadas infestações com plantas daninhas, pois por ocasião da emergência das plantas de milho, as plantas daninhas já estarão na fase de crescimento acelerado, utilizando precocemente os recursos do meio. Em soja (Glycine max), FLECK et al. (2002) verificaram que quanto maior é o atraso da semeadura em relação à dessecação da aveia preta, maiores são as reduções de produtividade de grãos decorrentes da interferência exercida por plantas de guanxuma (Sida spp.). Segundo os mesmos autores, o nível de dano econômico para guanxuma em soja é cerca de dez vezes maior quando a cultura foi semeada três dias após a dessecação, comparativamente à semeadura da cultura 11 dias após a dessecação da aveia preta.

Em adição, RIZZARDI et al. (2003) concluíram que o atraso na semeadura da soja, em relação à dessecação da cobertura vegetal no sistema de plantio direto, aumenta as perdas de rendimento de grãos decorrentes da interferência de guanxuma e picão-preto (Bidens spp.). Esses dados evidenciam a grande importância da época de emergência relativa entre cultura e plantas daninhas na determinação do potencial de dano ocasionado pelas últimas.

Quando o agricultor decide realizar a dessecação antecipada, mais que 20 dias antes da semeadura da cultura do milho, uma alternativa é realizar mais uma dessecação no momento da semeadura, a fim de controlar plantas daninhas que emergiram após a primeira dessecação. No entanto, essa prática aumenta os custos da lavoura, o impacto ambiental e a probabilidade de aparecimento de plantas daninhas resistentes ao ingrediente ativo utilizado, que na maioria das vezes é o glyphosate.

A redução do intervalo de tempo entre a dessecação das coberturas de inverno e a semeadura de milho pode diminuir a infestação de plantas daninhas, devido ao atraso de estabelecimento dessas plantas em relação à cultura. Portanto, o objetivo desse trabalho foi avaliar o efeito de épocas de dessecação de duas coberturas do solo de inverno em relação à semeadura do milho sobre a infestação de plantas daninhas e sobre a produtividade da cultura.

\section{MATERIAL E MÉTODOS}

O experimento foi conduzido em campo, no município de Canoinhas, SC, na safra 2004/05. A semeadura das culturas de cobertura foi realizada a lanço no dia 18/06/2004. As sementes foram incorporadas ao solo com auxílio de enxada. As culturas de cobertura utilizadas foram: azevém, em cultivo solteiro, ( 600 plantas $\mathrm{m}^{2}$ ), e o consórcio entre azevém, aveia preta, centeio, nabo forrageiro e ervilhaca comum $\left(178,70,70,20\right.$ e 17 plantas $\mathrm{m}^{-2}$, respectivamente). Não se utilizaram fertilizantes no cultivo das culturas de cobertura, pois na prática, a maioria dos agricultores realiza a fertilização somente no momento da semeadura das culturas de verão.

As características do solo no momento da implantação das culturas de cobertura eram as seguintes: argila $=50 \% ; \mathrm{pH}_{\text {áqua }}=4,8$; índice $\mathrm{SMP}=$ 5,$4 ; \mathrm{P}=4,2 \mathrm{mg} \mathrm{dm}^{-3} ; \mathrm{K}=180 \mathrm{mg} \mathrm{dm}^{-3} ;$ matéria orgânica $=3,7 \% ; \mathrm{Al}=0,5 \mathrm{cmol}_{c} \mathrm{dm}^{-3} ; \mathrm{Ca}=8,0 \mathrm{cmol}_{c}$ $\mathrm{dm}^{-3} ; \mathrm{Mg}=2,4 \mathrm{cmol}_{\mathrm{c}} \mathrm{dm}^{-3} ; \mathrm{T}=19,54 \mathrm{cmol}_{\mathrm{c}} \mathrm{dm}^{-3} ; \mathrm{e} \mathrm{V}$ $=55,6 \%$.

O manejo da fitomassa foi realizado quimicamente com o sal de $\mathrm{N}$-(fosfonometil) glicina (glifosato), na dose de 720 g i.a. ha ${ }^{-1}$, em cinco épocas: $30,20,10,5$ e 1 dia antes da semeadura da cultura do milho (DAnS).

O delineamento experimental utilizado foi o de blocos casualizados, em esquema fatorial $2 \times 5$, 
com quatro repetições. Cada unidade experimental apresentou área total de $16 \mathrm{~m}^{2}(3,2 \times 5 \mathrm{~m})$ e área útil de $6,4 \mathrm{~m}^{2}(1,6 \times 4 \mathrm{~m})$. Semeou-se a cultivar de milho SCS 153-Esperança no dia 20/10/2004, em espaçamento de $0,8 \mathrm{~m}$ e densidade de 50 mil plantas ha $^{-1}$. As quantidades de fertilizantes aplicadas na base e em cobertura seguiram as recomendações da SOCIEDADE BRASILEIRA DE CIÊNCIA DO SOLO (2004). A adubação de base foi a seguinte: $25 \mathrm{~kg} \mathrm{ha}^{-1}$ de $\mathrm{N} ; 130 \mathrm{~kg} \mathrm{ha}^{-1}$ de $\mathrm{P}_{2} \mathrm{O}_{5}$ e $70 \mathrm{~kg} \mathrm{ha}^{-1}$ de $\mathrm{k}_{2} \mathrm{O}$. Para a adubação de cobertura, consideraramse as alternativas de cobertura do solo utilizadas e a produção de fitomassa de cada uma. Assim, na situação em que a cobertura foi o azevém, a dose de $\mathrm{N}$ em cobertura foi de $75 \mathrm{~kg} \mathrm{ha}^{-1}$ e quando a cobertura era o consórcio, a dose de $\mathrm{N}$ em cobertura foi de $65 \mathrm{~kg} \mathrm{ha}^{-1}$. O fertilizante nitrogenado utilizado foi a uréia, aplicada a lanço. As parcelas foram mantidas em presença de plantas daninhas durante todo o ciclo de desenvolvimento do milho.

Durante a condução do experimento foram feitas as seguintes determinações: produção de fitomassa seca da parte aérea pelas culturas de cobertura do solo, determinada nas diferentes épocas de manejo, em amostra de $0,25 \mathrm{~m}^{2}$ por parcela; densidade de plantas daninhas, determinada aos 36 dias após a semeadura (DAS) do milho em amostra de $0,25 \mathrm{~m}^{2}$ por parcela; fitomassa seca da parte aérea das plantas daninhas aos 36, 55 e 103 DAS, em amostra de $0,25 \mathrm{~m}^{2}$ por parcela; e, produtividade de grãos de milho, estimada pela colheita das espigas contidas na área útil de cada parcela, as quais foram trilhadas e os grãos pesados. Os dados de produtividade foram corrigidos para $13 \%$ de umidade.

Os dados coletados foram submetidos à análise de variância e a existência de efeitos significativos de tratamentos foi determinada pelo teste F. Posteriormente, realizou-se análise de regressão polinomial. Selecionaram-se os modelos que apresentaram melhor ajuste aos dados e aos fenômenos analisados. O nível de probabilidade do erro adotado para as análises foi de $5 \%$.

\section{RESULTADOS E DISCUSSÃO}

Durante o desenvolvimento da cultura de milho, as principais espécies daninhas presentes no eperim €toforam papuã (Brachiaria plantaginea), picão-preto (Bidens spp.) e leiteira (Euphorbia heterophylla).

Não houve efeito significativo do tipo de cobertura do solo e da interação entre tipo de cobertura e época de dessecação sobre a fitomassa acumulada pela cobertura vegetal. Houve uma redução linear da fitomassa da cobertura vegetal com o aumento do intervalo de dias antes da semeadura (DAnS) do milho (Figura 1). Isso ocorreu porque aos 30 DAnS do milho o azevém, a aveia e a ervilhaca ainda estavam na fase de florescimento, podendo acumular mais fitomassa com a evolução do ciclo de desenvolvimento.

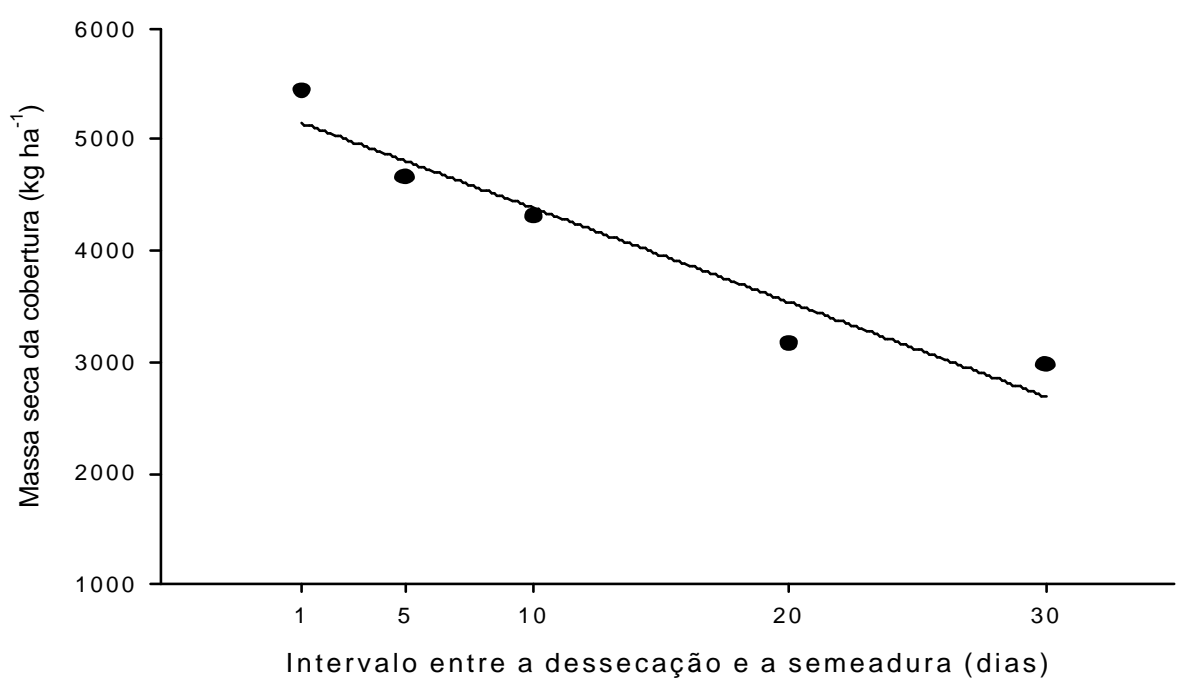

FIGURA 1 - Massa seca acumulada pelas coberturas de solo em diferentes momentos em relação à semeadura da cultura de milho. $y=5232-84,7 \times \cdot R^{2}=0,90$.

No experimento, verificou-se que o tipo de cobertura do solo e a interação entre o tipo de cobertura e a época de dessecação não apresentaram efeito sobre a $\mathrm{d}=$ ensidade de plantas daninhas determinada aos 36 DAS. Todavia, o efeito principal de época de dessecação foi significativo.
Com o aumento do intervalo entre a dessecação e a semeadura do milho houve incremento da densidade de espécies daninhas gramíneas, latifoliadas e total (Figura 2). Esse comportamento deve-se ao fato de que quanto maior é o intervalo entre a dessecação e a implantação da cultura, maior a disponibilidade de 
tempo para que haja a expressão do banco de sementes de plantas daninhas presente no solo. Outro fator a ser considerado, é que na dessecação próxima à semeadura, as coberturas do solo haviam acumulado mais fitomassa seca (Figura 1). Segundo BALBINOT et al. (2003), há correlação positiva entre quantidade de palha e supressão de plantas daninhas.

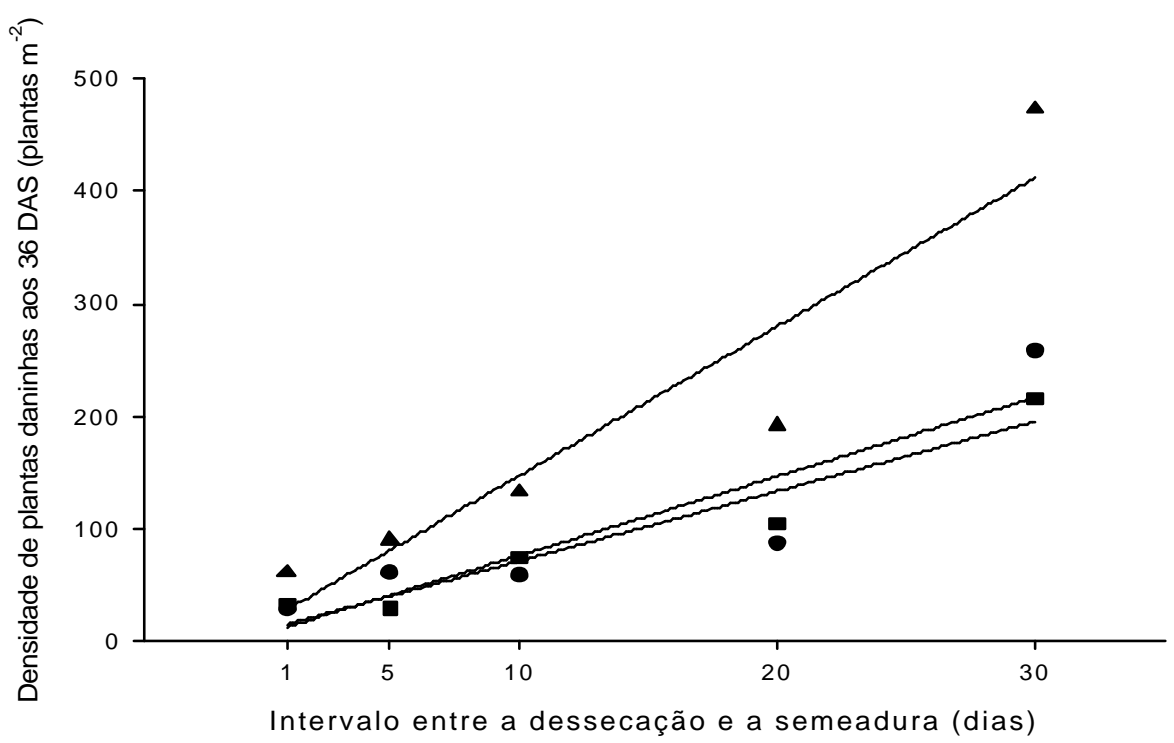

FIGURA 2 - Densidade de plantas daninhas determinada aos 36 dias após a semeadura da cultura de milho em diferentes intervalos entre a dessecação das coberturas do solo e a semeadura da cultura. gramíneas $\mathrm{y}=5,6+7,0 \mathrm{x} \cdot \mathrm{R}^{2}=0,76$. latifoliadas $\mathrm{y}=8,86+6,21 \mathrm{x} \cdot \mathrm{R}^{2}=0,90$. total $\boldsymbol{\Delta} \mathrm{y}=$ $14,46+13,25 x \cdot R^{2}=0,90$.

Contudo, em geral, a densidade de plantas daninhas não é a variável mais adequada para estimar o dano ocasionado por essas plantas às culturas de interesse econômico $(\mathrm{VI}=$ TTA et al., 1993). Uma variável que pode caracterizar mais adequadamente o dano que as plantas daninhas podem ocasionar nas culturas é a fitomassa acumulada pela plantas daninhas (PIKE et al., 1990). Isso ocorre porque parte dos recursos do ambiente que deveriam ser utilizados pelas culturas é usada para o crescimento das plantas daninhas.

Para as três épocas de avaliação da fitomassa de plantas daninhas (36, 55 e 103 DAS), não houve efeito do tipo de cobertura do solo e da interação entre tipo de cobertura e época de dessecação. Somente houve efeito da época de dessecação. Aos 36 DAS do milho, ainda foi possível separar a fitomassa produzida pelas espécies gramíneas e pelas espécies latifoliadas (Figura 3). Com a realização da dessecação com antecedência de 1 a aproximadamente 10 DAnS, não houve variação na fitomassa produzida pelas plantas daninhas gramíneas e latifoliadas. Porém, com antecedência superior a 10 dias, houve aumento acentuado da fitomassa infestante. Aos 55 DAS, o comportamento foi similar (Figura 4). Já, aos 103 DAS a produção de fitomassa pelas plantas daninhas, frente a diferentes épocas de manejo das coberturas em relação à semeadura do milho, apresentou comportamento linear (Figura 5). 


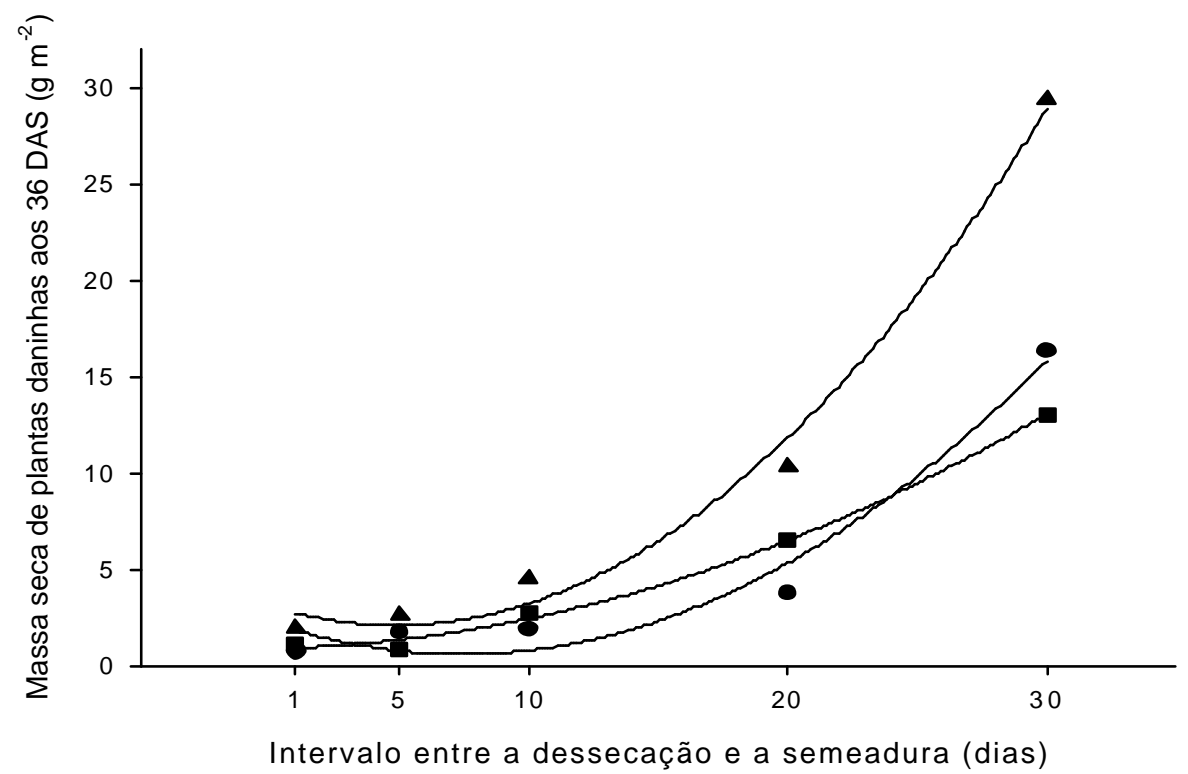

FIGURA 3 - Massa seca de plantas daninhas gramíneas, latifoliadas e total determinada aos 36 dias após a semeadura da cultura do milho em diferentes intervalos entre a dessecação das coberturas do solo e a semeadura da cultura. gramíneas $y=2,27-0,44 x+0,029 x^{2} \cdot R^{2}=0,92$. latifoliadas $y=0,87+0,03 x+0,0125 x^{2} \cdot R^{2}=0,90$. $\Delta$ total $y=3,10-0,41 x+0,04 x^{2} \cdot R^{2}=0,98$

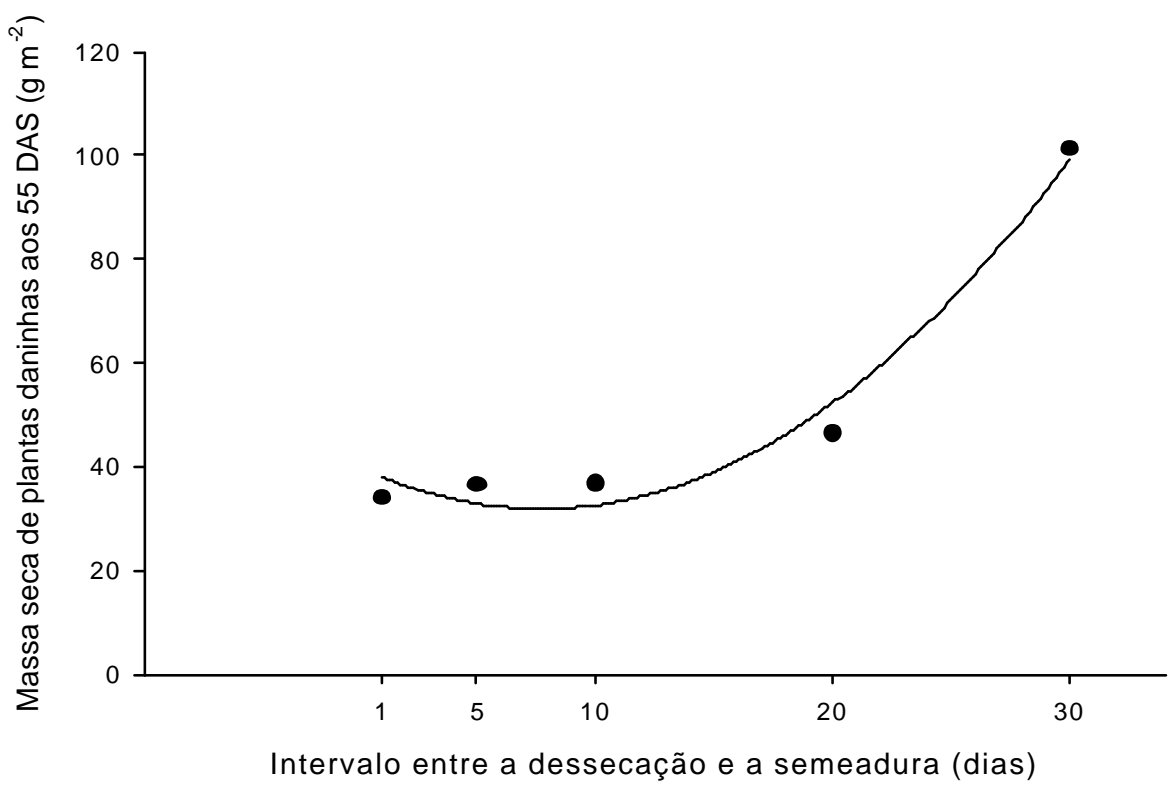

FIGURA 4 - Massa seca de plantas daninhas determinada aos 55 dias após a semeadura da cultura do milho em diferentes intervalos entre a dessecação das coberturas do solo e a semeadura da cultura. $y=40,12-2,09 x+0,13 x^{2} \cdot R^{2}=0,95$. 
BALBINOT JR, A.A. et al. Épocas de dessecação...

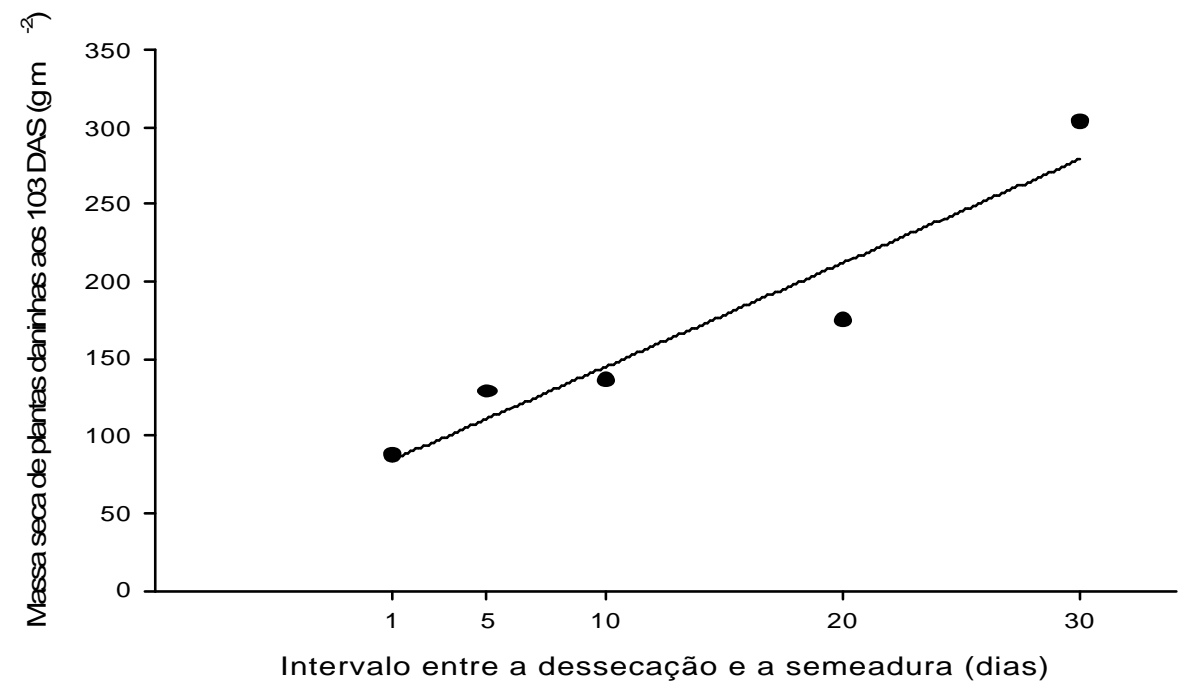

FIGURA 5 - Massa seca de plantas daninhas determinada aos 103 dias após a semeadura da cultura do milho em diferentes intervalos entre a dessecação das coberturas do solo e a semeadura da cultura. $y=77,6+6,7 x \cdot R^{2}=0,88$

O aumento da fitomassa de plantas daninhas em decorrência da adoção de maiores intervalos entre a dessecação da cobertura e a semeadura do milho, provavelmente, seja conseqüência da maior densidade de plantas daninhas quando houve dessecação precoce (Figura 2) e, principalmente, devido ao estabelecimento antecipado das plantas daninhas em relação às plantas de milho. Plantas que se estabelecem primeiro no ambiente levam vantagem na competição pelos recursos do ambiente (água, luz e nutrientes) (FISCHER e MILES, 1973; KNEZEVIC et al., 1994; KNEZEVIC et al., 1995; RADOSEVICH et al., 1997; BALBINOT et al., 2001).

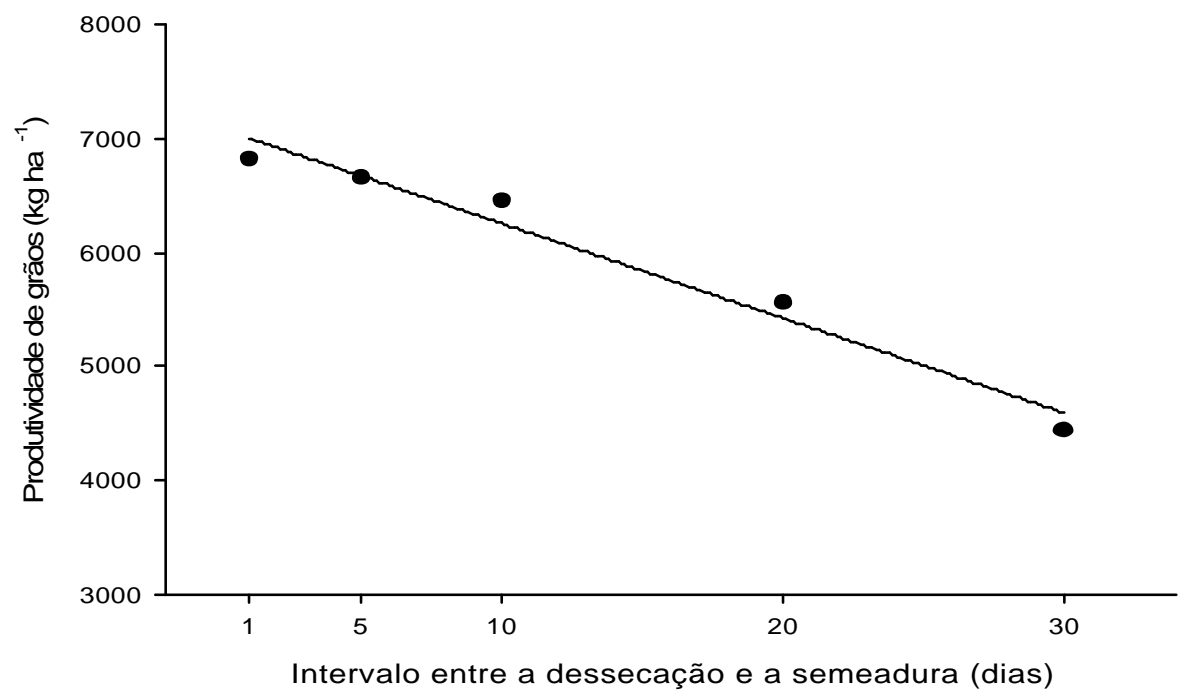

FIGURA 6 - Produtividade de grãos de milho em diferentes intervalos entre a dessecação das coberturas do solo e a semeadura da cultura. $y=7090-83,2 x \cdot R^{2}=0,96$ 
Para produtividade de grãos, houve efeito significativo somente da época de dessecação. Devido à menor interferência exercida pelas plantas daninhas em dessecação próxima à semeadura, houve maior produtividade de grãos nessa situação. A cada dia de aumento no intervalo entre a dessecação e a semeadura do milho, houve redução de produtividade em 83,2 $\mathrm{kg} \mathrm{ha}^{-1}$ (Figura 6).

A dessecação da cobertura próxima à semeadura do milho é uma estratégia importante no manejo integrado de plantas daninhas, pois favorece o estabelecimento precoce das plantas de milho em relação às mesmas. Entretanto, quando há uso de gramíneas para cobertura do solo, a dessecação próxima à semeadura do milho pode ocasionar redução de suprimento de nitrogênio à cultura no momento de maior requerimento desse nutriente (MYN et al., 2000). Devido à interação entre manejo de plantas daninhas e manejo nutricional da cultura do milho, a dessecação da cobertura próxima à semeadura do milho é importante e pode ser usada na prática em situações em que há elevado banco de sementes de espécies daninhas e adequado teor de matéria orgânica no solo, como fonte de nitrogênio. Além disso, é importante considerar que o manejo das coberturas próximo à semeadura do milho pode, em alguns casos, intensificar reações alelopáticas na cultura do milho em decorrência da liberação de aleloquímicos pela palha.

Outros fatores a serem considerados na adoção de dessecações próximas à semeadura é que, nessa situação, pode haver sombreamento à cultura imposto pela maior quantidade de cobertura e dificuldade de realizar a semeadura quando a cobertura ainda não está seca. Esses fatores devem ser analisados com o intuito de dar suporte à tomada de decisão sobre a viabilidade de realizar a dessecação em um intervalo não superior a dez dias da semeadura.

\section{CONCLUSÃO}

Redução no intervalo entre a dessecação da cobertura do solo de inverno e a semeadura do milho diminui a infestação de plantas daninhas estivais, o que proporciona maior produtividade de grãos de milho.

\section{REFERÊNCIAS}

1. BALBINOT JR., A.A.; FLECK, N.G.; AGOSTINETTO, D.; RIZZARDI, M.A.; MEROTTO JR., A.; VIDAL, R.A. Velocidade de emergência e crescimento inicial de cultivares de arroz irrigado influenciando a competitividade com as plantas daninhas. Planta Daninha, Viçosa, v. 19, n. 3, p. 305-316, 2001

2. BALBINOT JR., A.A.; FONSECA, J.A.; TÔRRES, A.N.L. BAVARESCO, A. Palha de ervilhaca em cobertura morta do solo afeta a incidência de plantas daninhas e a produtividade do milho. Revista de Ciências Agroveterinárias, Lages, v. 2, n. 1, p. 42-49, 2003

3. BALBINOT JR., A.A.; BIALESKI, M.; BACKES, R.L. Épocas de manejo de plantas de cobertura do solo de inverno e incidência de plantas daninhas na cultura do milho. Revista Agropecuária Catarinense, Florianópolis, v. 18, n. 3, p. 91-94, 2005.

4. CONSTANTIN, J.; OLIVEIRA JR., R.S. de; MARTINS, M.C.; LOPES, P.V.; BARROSO, A.L.L. Dessecação em áreas com grande cobertura vegetal: alternativas de manejo. Informações Agronômicas, Piracicaba, n. 111, p. 7-9, 2005.

5. FISCHER, R.A.; MILES, R.E. The role of spatial pattern in the competition between crop plants and weeds. A theoretical analysis. Mathematical Biosciences, New York, v. 18, p. 335-350, 1973.

6. FLECK, N.G.; RIZZARDI, M.A.; VIDAL, R.A.; MEROTTO JR., A.; AGOSTINETTO, D.; BALBINOT JR., A.A. Período crítico para controle de Brachiaria plantaginea em função de épocas de semeadura da soja após a dessecação da cobertura vegetal. Planta Daninha, Viçosa, v. 20, n. 1, p. 53-62, 2002.

7. KNEZEVIC, S.Z.; WEISE, S.F.; SWANTON, C.J. Interference of redroot pigweed (Amaranthus retroflexus) in maize (Zea mays). Weed Science, Lawrence, v. 42, n. 4, p. 568-573, 1994

8. KNEZEVIC, S.Z.; WEISE, S.F.; SWANTON, C.J. Comparison of empirical models depicting density of Amaranthus retroflexus L. and relative leaf area as predictors of yield loss in maize (Zea mays L.). Weed Research, Oxford, v. 35, n. 4, p. 207 214, 1995

9. PIKE, D.R.; STOLLER, E.W.; WAX, L.M. Modeling soybean growth and canopy apportionment in weed-soybean ( Glycine max) competition. Weed Science, Champaign, v. 38, n. 6, p. 522-527, 1990.

10. RADOSEVICH, S.; HOLT, J.; GHERSA, C.Weed Ecology. 2. ed. New York: Wiley, 1997. 588p.

11. RIZZARDI, M.A.; FLECK, N.G.; AGOSTINETTO, D.; BALBINOT JR., A.A. Previsão da perda de rendimento de grãos de soja causada pela infestação de plantas daninhas utilizando variáveis foliares relativas. Planta Daninha, Viçosa, v. 21, n. 1, p. 45$54,2003$.

12. ROMAN, E.S. Plantas daninhas: manejo integrado na cultura do milho e de feijão. Revista Plantio Direto, Passo Fundo, v. 72 , 2002. Disponível em: <http://www.plantiodireto.com.br/?body=cont_int\&id=400>. Acesso em 25 MAR 2003.

13. SEVERINO, F.J.; CHRISTOFFOLETI, P.J. Efeitos de quantidades de fitomassa de adubos verdes na supressão de plantas daninhas. Planta Daninha, Viçosa, v. 19, n. 2, p. 223-228, 2001.

14. SOCIEDADE BRASILEIRA DE CIÊNCIA DO SOLO. Comissão de química e fertilidade do solo. Manual de adubação e calagem para os Estados do Rio Grande do Sul e de Santa Catarina. 10 ed. Porto Alegre, 2004. 394 p.

15. TREZZI, M.M.; VIDAL, R.A. Potencial de utilização de cobertura vegetal de sorgo e milheto na supressão de plantas daninhas em condição de campo: II Efeitos da cobertura morta. Planta Daninha, Viçosa, v. 22, n. 1, p. 1-10, 2004.

16. VIDAL, R.A.; TREZZI, M.M. Potencial da utilização de coberturas vegetais de sorgo e milheto na supressão de plantas daninhas em condição de campo: I Plantas em desenvolvimento vegetativo. Planta Daninha, Viçosa, v. 22, n. 2, p. 217-223, 2004.

17. VITTA, J.I.; SATORRE, E.H.; LEGUIZAMON, E.S. Using canopy attributes to evaluate competition between Sorghum halepense (L.) Pers. and soybean. Weed Research, Oxford, v. 33, n. 1, p. 89-97, 1993.

18. VYN, T.J.; FABER, J.G.; JANOVICEK, K.J.; BEAUCHAMP, E.G. Cover crop effects on nitrogen availability to corn following wheat. Agronomy Journal, Madison, v. 92, n. 5, p. 915-924, 2000.

Recebido em 05/07/2006 Aceito em 23/05/2007 
